\title{
The old country doctor
}

D r. Joseph Roach was not a man to get up and talk. He said goodbye to his last afternoon patient, "well, I'll see ya then, eh?" and met Hughena, his secretary, at the reception desk. Dressed in his usual blue pinstripe suit and brown brogues, he looked toward the ceiling and rehearsed his speech: "Needless to say ..."

He listed off all the people he worked with, a nice thing to say about each one. Not a soul was left out, from the highest up in the hospital to the person that swept the floor.

"If I had to do it again, I would do it," he chuckled, "sadly, all the same."

"Well?" Roach looked to Hughena, “did I miss anyone?" He recited it over, and over again.

Roach grew up just outside New Waterford, in the Cape Breton region of Nova Scotia, on the Lingan Road where the houses tuck neatly into the quilted forest. In the fall it becomes a patchwork of pumpkin, cranberry, copper and rust, with a stippling of dark forest pine. In the town, the colourful box-shaped houses stand against a backdrop of open Atlantic. Ashes in the yards were once a sign of New Waterford's trade, coal mining.

Roach, like many of his friends, dropped out of high school to work in the mines. From September until January he worked mine number 16 and did all the jobs, from loading, to boring, to chain-running. But he soon realized that life in the mine was difficult and dangerous.

Roach schooled himself in Latin at home and came out head of his class. He received a W.K. Kellogg Foundation scholarship to study medicine at Dalhousie University in Halifax and spent his summers working the mine and saving money. The miners got word that Roach was studying medicine and never let him do a job that would risk his hands.

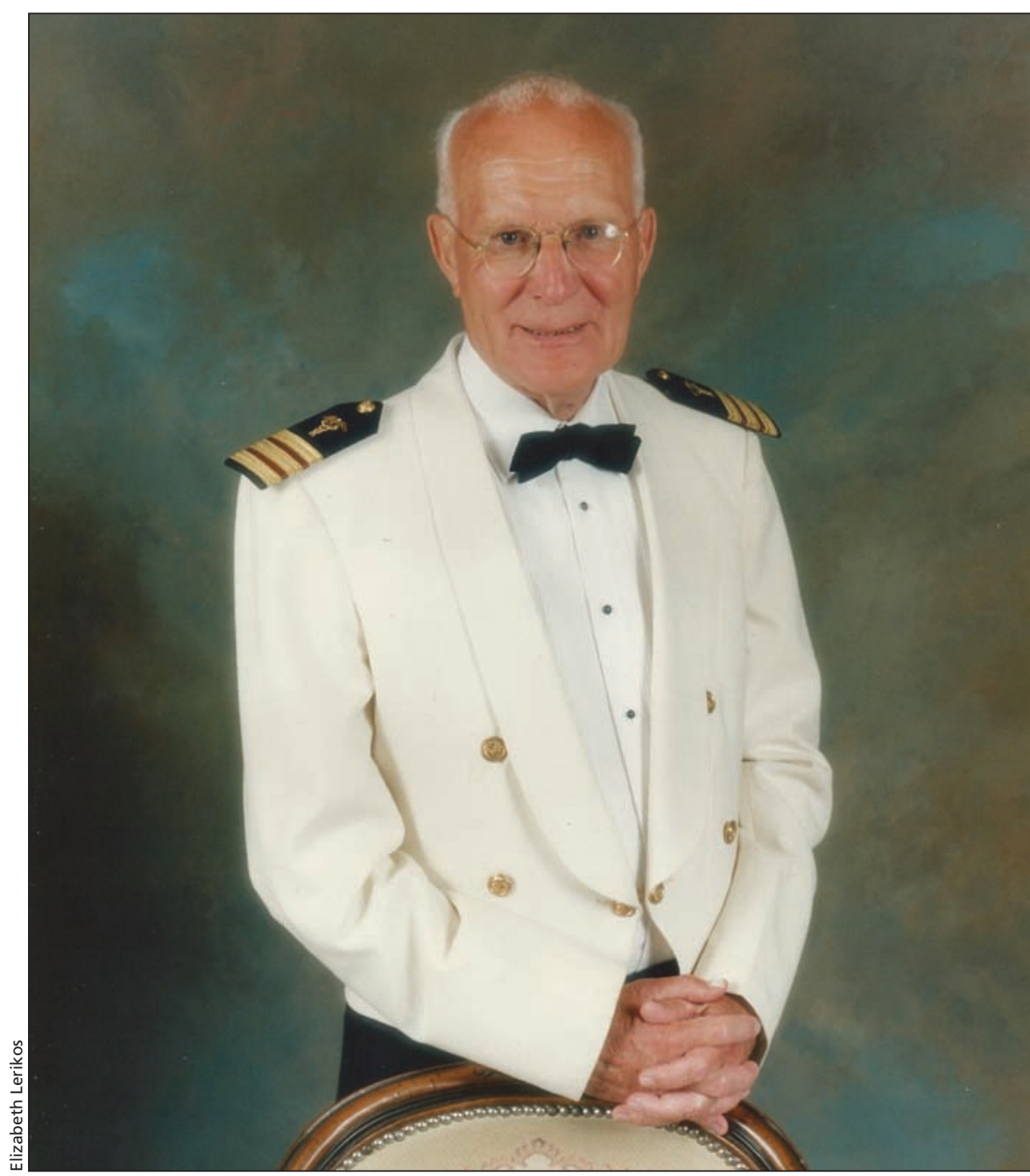

Upon retirement, Dr. Roach embarked on another journey, becoming a cruise-ship doctor at age 79. Approximately 18 months later, at the request of the Minister of Health, Dr. Roach returned to his practice to help alleviate a physician shortage, continuing his life-long commitment to the people of New Waterford.

"We'll take care of you," they said, "so that you can take care of us."

Roach came back to New Waterford on Dec. 28, 1948 to work at the New Waterford General Hospital on Plummer Avenue. Back then Plummer Avenue had everything, an Eaton's, a cooperative store, a cobbler and a bakery, with the New Waterford General Hospital right in the middle. At King and Plummer, or Strand Corner, stood a hall where you went for dances and a band played popular music with piano, guitar, fiddle and drums. You could go to King's for a soda, or to Dan Willie's brother's barber shop for a chat. Harry Yip's for french fries and gravy was the treat. The Majestic was the theatre and the Five and Ten was the original fiveand-dime store.

Fifty years later, the coal ashes have blown from the New Waterford yards 
and the coloured shingles are faded. The last mine shut down years ago and the young people have flown West to find work. On Plummer Avenue are Whisky's Bar and Grill, a Tim Horton's and a Bargain store. On Strand Corner there is a car wash.

The only thing that didn't change in New Waterford was Roach. At 83 years he saw 40 patients a day and 12000 patients a year. He finished assisting an neath to free Bryan. His left leg was crushed, flat underneath his back; his ankle pressed between his shoulder blades. The sump pump needed power to work and water started filling the rooms of the mine. They called for an emergency run and sent for the diesel engine with cables to run power to the mine and get Bryan out. The chain runner rushed to get the man rake hooked up and waited for the doctor.

\section{"We'll take care of you, so that you can take care of us."}

operation and then treated an emergency patient. He delivered a baby, headed up to see patients in the office, and did 12 to 15 house calls on his way home.

Roach delivered 3500 New Waterforders over 57 years, and he remembered the details of every one. He loved to tell the story of Bryan McDonald's birth. He and Bryan's mother were in school together in the 1930s.

"January 8th, 1950," Roach told Bryan, "it was a wicked snowstorm, and your mother was taken to the hospital in a snowplough." Bryan's father was town councillor at the time; he called the snowplough driver to take his wife to hospital.

Bryan grew up to join the men in the mines, and Roach delivered both of Bryan's sons. Just after Easter 1979, Bryan was working in the mine to put a new cable on a trolley. He was lying next to the mechanic under the belt line when the main transformer blew and the power went out. The bright torch dancing on each miner's head the only source of light.

The supervisor overman working at the top of the shaft waited for the pitlamp signal before pushing the trolley button. Up and down meant ready; side to side meant wait. The mechanic crawled out first, stood up and unintentionally tilted his head up and down. The overman released the trolley. Bryan, still lying underneath the cable, felt it tighten as the trolley sped down the track. He tried to jump, but was too late. It hit once, bounced back and hit a second time. The miners quickly grabbed hold of a rail and slid it under-
When the hospital got a call from the mine Roach grabbed his stethoscope and his grip, the black leather medical bag, and raced down to the pit in his old yellow Oldsmobile.

Always the gentleman, he arrived in a three-piece suit, grip in hand. Roach flung off his hat, threw on a pair of orange coveralls and a headlamp, and jumped into the rake to travel down the main deeps.

For 20 minutes they lowered through the dark, damp rooms of the mine. It took another 15 minutes to walk to the coal face, thousands of feet beneath the sea. Roach rushed to the injured miner's side, talking without pause, keeping the patient awake while the miners carried him out on a stretcher.

Bryan reached the surface an hour later. "Jumpin' Jesus, Christ Almighty!" exclaimed Roach. "Why did they do the likes of this to you?" Bryan was in shock and his blood pressure was low. His blue leg swelled as if it was filling up with jelly and as the skin stretched it started to tear. Roach took a cream out of his medical bag, rubbed it onto the leg, and said, "I'm going to stick a needle in, Bryan, so bite your teeth and make a fist."

Roach injected Bryan's hip with analgesics and then took a large syringe to drain some fluid off the leg. He removed five large syringes full of fluid and arranged for Bryan to be transferred to Halifax. "Don't worry son," said Roach, "we'll get this fixed."

It was a stunning day in June with not a cloud in the sky. The Mount Carmel Auditorium was filled with 400 New Waterforders excited to celebrate 83-year-old Roach. Bryan McDonald had wanted to come and thank Roach for saving his leg but he was now working security and had a shift that night.

Roach and his wife Helen were escorted to a corner with two wingback chairs, a coffee table and a lamp. Helen sat and Roach stood by her side. Hundreds lined up to say their thanks. His ice-blue eyes glistened through thinrimmed glasses as Roach greeted each thank you - YYou're the best," "Isn't this great?" - with a pat on the arm, a hug and a smile.

The room was transformed, with hundreds of glittering white lights and silver tinsel on the walls. A white canopy hung from the ceiling and long tables were set with linen for the dinner.

Roach stood and the crowd rose with applause. His sunned skin wrinkled as he flashed a gold-toothed smile. "He was just aglow," recalled Hughena.

Roach looked down nervously and lifted his hands from his sides into his pockets. The crowd quietened as he moved to the podium, firmly grasping its wooden sides.

"Needless to say," started Roach, "medicine is an art that requires a number of different people." He swayed anxiously back and forth and glanced for a moment to Hughena. "I can see a look of panic on his face," she thought. But his eyes calmed and he smoothly recited his speech. He thanked the nurses, the switchboard operators and the housekeeping staff.

"Last but not least," he smiled softly, "my wife and family. I apologize for the missed meals."

Roach looked to the crowd, "To the people of New Waterford, you are the best in the world, and it was a pleasure to serve you."

"If I had to do it again, I would do it," he chuckled, "sadly, all the same."

Dr. Joseph Aloysius Roach worked as a family doctor in New Waterford from 1948 until 2004. He died at home in his sleep, aged 85, on Sept. 5, 2005.

\section{Chryssa McAlister MD \\ Department of Ophthalmology \\ and Vision Sciences, \\ University of Toronto, \\ Toronto, Ont.}

CMAJ 2013. DOI:10.1503/cmaj.121918 